\title{
Water remediation by metallic iron: Much ado about nothing - As profitless as water in a sieve?
}

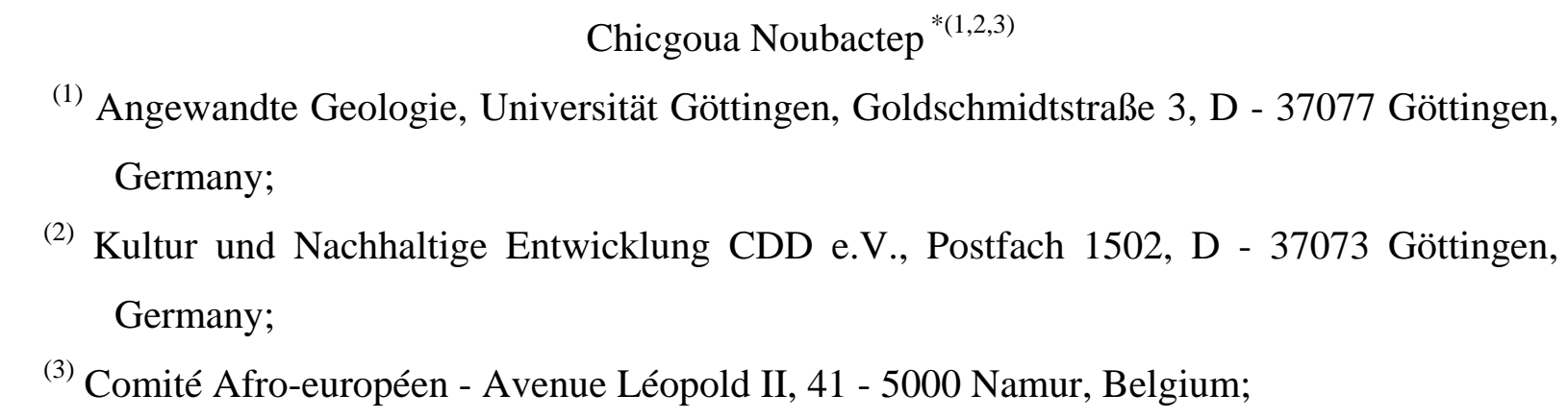

(1) Angewandte Geologie, Universität Göttingen, Goldschmidtstraße 3, D - 37077 Göttingen, Germany;

(2) Kultur und Nachhaltige Entwicklung CDD e.V., Postfach 1502, D - 37073 Göttingen, Germany;

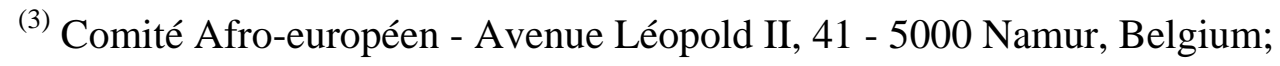

Running title: Interdisciplinary approach gone astray? Save the peer-review system.

${ }^{*}$ Correspondance address:

PD Dr. Chicgoua Noubactep

Geologie, Universität Göttingen, Goldschmidtstraße 3, D - 37077 Göttingen, Germany

e-mail: cnoubac@gwdg.de

Tel. +495513933191

Fax: +49551399379

Keywords: Interdisciplinary approach, Peer-review system, Permeable reactive barrier, Water treatment, Zero-valent iron. 
Water remediation by metallic iron: Much ado about nothing - As profitless as water in

a sieve?

Chicgoua Noubactep

Angewandte Geologie, Universität Göttingen, Goldschmidtstraße 3, D-37077, Göttingen, Germany.

Kultur und Nachhaltige Entwicklung CDD e.V., Postfach 1502, D-37005 Göttingen, Germany.

Comité Afro-européen - Avenue Léopold II, 41 - 5000 Namur, Belgium.

e-mail: cnoubac@gwdg.de; Tel. +49 55139 3191, Fax: +49 551399379.

There has been much ado about water treatment with metallic iron $\left(\mathrm{Fe}^{0}\right)$ since the early 1990s. Thousands of articles, books, papers and technical reports have been written (i) describing laboratory feasibility tests, pilot plant performances and field implementations from around the world, (ii) outlining fundamental causes of failure (if applicable), and (iii) suggesting changes for more efficient $\mathrm{Fe}^{0}$ systems [1,2]. However, crucial knowledge about the operating mode of $\mathrm{Fe}^{0}$-based systems is still lacking. In other words, fundamental knowledge necessary for the proper design of more efficient $\mathrm{Fe}^{0}$ remediation systems is still largely ignored [3]. To fill this knowledge gap and exploit the huge potential of $\mathrm{Fe}^{0}$ for water treatment, it is urgent to use a scientifically-based, truly interdisciplinary approach. Such a comprehensive, holistic and inclusive approach will unify a sound community in the quest of more efficient $\mathrm{Fe}^{0}$ remediation systems. This argumentation is not new as the funding policy of several agencies is based on 'interdisciplinary approach'. In other words, an interdisciplinary approach is already largely followed. Yet still severe crises are encountered, in particular concerning the mechanism of contaminant removal in $\mathrm{Fe}^{0} / \mathrm{H}_{2} \mathrm{O}$ systems or even, concerning the intrinsic nature of $\mathrm{Fe}^{0}$. Is $\mathrm{Fe}^{0}$ a stand-alone reducing agent or a parent of (adsorbing, enmeshing and) reducing agents? The discussion on the nature of $\mathrm{Fe}^{0}$ is now lasting more than 6 years [4] but is still largely profitless. It seems, there is a lack of willingness to test new ideas even though the comfortable one is obviously not efficient. 
53 The technology of treating water with $\mathrm{Fe}^{0}$ was born with the spurious perception, that $\mathrm{Fe}^{0}$ is a 54 reducing agent [5]. This illusive view would have challenged almost a 200-years-old knowledge on the electrochemical nature of aqueous corrosion [6,7] and almost 100 years expertise from intensive research on aqueous iron corrosion [8]. In 1923, Ulick Richardson Evans (1889-1980) has provided a modern understanding of the corrosion process based on the electrochemical theory. Fortunately, the pioneers of the technology have not explicitly challenged the electrochemical theory of aqueous iron corrosion. They have simply ignored it and built a self-satisfactorily 'knowledge system' regarding $\mathrm{Fe}^{0}$ as a reducing agent. This knowledge system can not explain why chemical species without any redox properties have been quantitatively removed in $\mathrm{Fe}^{0} / \mathrm{H}_{2} \mathrm{O}$ systems. Moreover, for $\mathrm{Fe}^{0}$ to act as a reducing agent, electrons from the metal body should be relayed to the species of concern (including contaminants) by electronic conductive phases [5]. However, neither the multi-layer oxide scale on iron is conductive nor natural organic materials have been (univocally) positively tested as 'electron shuttles' [9-13]. In fact, the model of oxide scale generation and evolution sustaining the 'reductive transformation' concept [9] was proven inconsistent by Odziemkowski and colleagues [10-12]. Moreover, although magnetite films $\left(\mathrm{Fe}_{3} \mathrm{O}_{4}\right)$ are electronic conductive in nature, the whole oxide scale on $\mathrm{Fe}^{0}$ is always made of several layers including layers of $\mathrm{Fe}^{\mathrm{III}}$-species [14-16]. This evidence makes quantitative electron transfer from the metal body to species adsorbed at the outer surface of the oxide scale unlikely. In other words, all 'crutches' that have supported the introduction of the illusive concept have been proven false, but the concept is still miraculously alive.

A cursory look at the literature on remediation with $\mathrm{Fe}^{0}$ reveals a vast scholarship originating from diverse disciplines and using $\mathrm{Fe}^{0}$ of various types and sizes for multiple goals (e.g. environmental remediation, drinking water production, soil cleaning, wastewater treatment) [17-19]. The acronym "zero-valent iron" is used to designate elemental/metallic iron. That is iron in the oxidation state zero $\left(\mathrm{Fe}^{0}\right)$. The term 'valence' in "zero-valent iron” is wrongly 
used. This misleading acronym is anterior to the $\mathrm{Fe}^{0}$ remediation technology. However, $\mathrm{Fe}^{0}$ is (still almost) univocally used as electron source for contaminant reductive transformation. Current and past researches aim to improve the understanding of interactions within the $\mathrm{Fe}^{0} / \mathrm{H}_{2} \mathrm{O}$ system, such that more efficient systems could be designed. It is obvious that no real improvement is possible when the intrinsic nature of $\mathrm{Fe}^{0}$ is not established/recognized [20].

The intrinsic nature of aqueous metal corrosion is summarized in a paper by Sato [21] in the following terms: "Metallic corrosion produces a layer of corrosion precipitates on the metal surface in aqueous solutions. The interfacial layer thus produced influences the corrosion of underlying metals depending on its ionic and electronic properties. The presence of a gel-like or porous precipitate layer of insoluble rusts such as hydrous metal salts or oxides causes either accelerated metallic corrosion or passivation”. This text recalls that iron is corroded by water and that the $\mathrm{Fe}^{0}$ surface is covered by oxide layers. These layers are non conductive as a rule. Accordingly, regardless from the background of any active researcher, his primary work should consist on elucidating how such a system will behave in the presence of target species, including the contaminants. If such an approach was adopted, a false concept would have not been introduced in the 1990s. Moreover, an alternative view would have not remain 7 years mostly untested.

Arguments against the alternative view are numerous and include the following: (i) the prevailing concept is well accepted, (ii) it is not worth to look nearly into the matter, (iii) the author has not presented experimental results, (iv) the author has already published this argument in other forums, (v) no better support of old arguments are given, and (vi) related articles appeared in 'low impact journal'. Taken together this argumentation is not based on scientific facts and has even not really addressed the crucial point: the reductive transformation concept is simply false. The best pseudo-scientific argument will not correct this mistake. A more scientific attitude recommends that the inherently wrong concept is 
abandoned and the alternative, already positively tested by few researchers [20,22-24] is

105 considered as the new compass in exploring the $\mathrm{Fe}^{0} / \mathrm{H}_{2} \mathrm{O}$ universe.

106 There is indeed much ado about the operating mode of $\mathrm{Fe}^{0} / \mathrm{H}_{2} \mathrm{O}$ systems, as there should be.

107 The critical issue of this discussion is the mechanism of contaminant removal. This issue is 108 elegantly solved by simply properly considering the iron corrosion literature [14-16]. 109 Alternatively, the thermodynamics of iron oxidative dissolution and the subsequent 110 precipitation of iron phases can be considered. Instead of arguing with examples, scientists 111 should have trusted the expertise of their colleagues who are closer in their academic 112 background to electrochemistry $[25,26]$. Thus, it is argued that the operating mode of $\mathrm{Fe}^{0} / \mathrm{H}_{2} \mathrm{O}$ 113 systems must be addressed comprehensively through sound interdisciplinary studies. In this 114 effort, expertise of individual scientists should be respected. If individual expertise is not 115 respected, the vast array of 'scientific' studies may just seep though the sieve of intellectual selfishness. This intellectual selfishness is as profitless as water in a sieve $[27,28]$. To conclude, the German thinker, Johann Wolfgang von Goethe (28.08.1749 - 22.03.1832)

118 will be quoted: "In the sciences, people quickly come to regard as their own personal 119 property that which they have learned and had passed on to them at the universities and 120 academies. If someone else comes along with new ideas that contradict the Credo and in fact even threaten to overturn it, then all passions are raised against this threat and no method is left untried to suppress it. People resist it in every way possible: pretending not to have heard about it; speaking disparagingly of it, as if it were not even worth the effort of looking into the 124 matter. And so a new truth can have a long wait before finally being accepted." It is amazing, 125 perhaps also surprising, to realize that this observation is valid even for an evidence resulting 126 from a falsification of the mainstream corrosion science. It seems that the primordial 127 motivation for scientific publication is no more the scientific content but some common 128 'urgencies’ ("publish or perish"). Relevant 'urgencies’ include patents, promotions, proposal 129 success or salary increments [29]. "Publish or perish" is an excellent threatening reminder of 
130 the importance of the publication of scientific achievements. However, despite simplified 131 accessibility to scientific articles (e.g. SciFinder ${ }^{\circledR}$, Scopus ${ }^{\circledR}$, Web of Sciences ${ }^{\circledR}$ ) dealing with

$132 \mathrm{Fe}^{0}$, individual articles must be critically and impartially evaluated. In other words, the " So

133 what?'’ question [30] should always be in the mind of each author, if scientific progress is 134 sought.

135 Acknowledgements

136 Thanks are due to Sabine Caré (Laboratoire Navier (ENPC/IFSTTAR/CNRS) Paris/France)

137 for fruitful collaboration on the consideration of the expansive nature of iron corrosion. The 138 manuscript was improved by the insightful comments of anonymous reviewers from CLEAN 139 Soil, Air, Water.

\section{$140 \quad$ References}

141 [1] D. H. Phillips, T. Van Nooten, L. Bastiaens, M. I. Russell, K. Dickson, S. Plant, J. M. E. Ahad, T. Newton, T. Elliot, R. M. Kalin, Ten year performance evaluation of a field-scale zero-valent iron permeable reactive barrier installed to remediate trichloroethene contaminated groundwater. Environ. Sci. Technol. 2010, 44, 3861-3869.

[2] R. T. Wilkin, S. D. Acree, R. R. Ross, R. W. Puls, T. R. Lee, L. L. Woods, Fifteen-year assessment of a permeable reactive barrier for treatment of chromate and trichloroethylene in groundwater. Sci. Tot. Environ. 2014, 468-469, 186-194.

148 [3] C. Noubactep, Aqueous contaminant removal by metallic iron: Is the paradigm shifting? Water SA 2011, 37, 419-426.

[4] C. Noubactep, Processes of contaminant removal in " $\mathrm{Fe}^{0}-\mathrm{H}_{2} \mathrm{O}$ " systems revisited. The importance of co-precipitation. Open Environ. J. 2007, 1, 9-13.

[5] E.J. Weber, Iron-mediated reductive transformations: investigation of reaction mechanism. Environ. Sci. Technol. 1996, 30, 716-719.

154 [6] A. De la Rive, 1830, citation after Roberge [7]. 
155 [7] P. R. Roberge, Handbook of corrosion engineering. McGraw-Hill New York/San $156 \quad$ Francisco, 2000, 1130 pp.

157 [8] U. R. Evans, An Introduction to Metallic Corrosion. London, Edward Arnold Ltd., 3nd ed., 1981, 302 pp.

[9] M.M. Scherer, S. Richter, R.L. Valentine, P.J.J. Alvarez, Chemistry and microbiology of permeable reactive barriers for in situ groundwater clean up. Rev. Environ. Sci. Technol. 2000, 30, 363-411.

[10] K. Ritter, M.S. Odziemkowski, R.W. Gillham, An in situ study of the role of surface films on granular iron in the permeable iron wall technology. J. Contam. Hydrol. 2002, 55, 87-111.

[11] M.S. Odziemkowski, R.P. Simpraga, Distribution of oxides on iron materials used for remediation of organic groundwater contaminants - Implications for hydrogen evolution reactions. Can. J. Chem. 2004, 82, 1495-1506.

[12] M. Odziemkowski, Spectroscopic studies and reactions of corrosion products at surfaces and electrodes. Spectrosc. Prop. Inorg. Organomet. Compd. 2009, 40, 385-450.

[13] F. Fu, W. Han, B. Tang, M. Hu, Z. Cheng, Insights into environmental remediation of heavy metal and organic pollutants: Simultaneous removal of hexavalent chromium and dye from wastewater by zero-valent iron with ligand-enhanced reactivity. Chem. Eng. J. 2013, 232, 534-540.

[14] M. Cohen, The formation and properties of passive films on iron. Can. J. Chem. 1959, 37, 286-291.

176 [15] M. Cohen, Thin oxide films on iron. J. Electrochem. Soc. 1974, 121, 191C-197C.

[16] S. Nesic, Key issues related to modelling of internal corrosion of oil and gas pipelines A review. Corros. Sci. 2007, 49, 4308-4338. 
[17] S. Comba, A. Di Molfetta, R. Sethi, A Comparison between field applications of nano-, micro-, and millimetric zero-valent iron for the remediation of contaminated aquifers. Water Air Soil Pollut. 2011, 215, 595-607.

[18] M. Gheju, Hexavalent chromium reduction with zero-valent iron (ZVI) in aquatic systems. Water Air Soil Pollut. 2011, 222, 103-148.

[19] A. Ghauch, G. Ayoub, S. Naim, Degradation of sulfamethoxazole by persulfate assisted micrometric $\mathrm{Fe}^{0}$ in aqueous solution. Chem. Eng. J. 2013, 228, 1168-1181.

[20] K. Miyajima, Optimizing the design of metallic iron filters for water treatment. Freiberg Online Geoscience 2012, 32, 60 pp.

[21] N. Sato, Surface oxides affecting metallic corrosion. Corros. Rev. 2001, 19, 253-272.

[22] M. Gheju, I. Balcu, Removal of chromium from $\mathrm{Cr}(\mathrm{VI})$ polluted wastewaters by reduction with scrap iron and subsequent precipitation of resulted cations. J. Hazard. Mater. 2011, 196, 131-138.

[23] S. Bilardi, P.S. Calabrò, S. Caré, N. Moraci, C. Noubactep, Improving the sustainability of granular iron/pumice systems for water treatment. J. Environ. Manage. 2013, 121, $133-141$.

[24] A. Ghauch, Iron-based metallic systems: An excellent choice for sustainable water treatment. Habilitation Thesis, University of Grenoble, France, 2013.

[25] E. Lipczynska-Kochany, S. Harms, R. Milburn, G. Sprah, N. Nadarajah, Degradation of carbon tetrachloride in the presence of iron and sulphur containing compounds. Chemosphere 1994, 29, 1477-1489.

[26] B. K. Lavine, G. Auslander, J. Ritter, Polarographic studies of zero valent iron as a reductant for remediation of nitroaromatics in the environment. Microchem. J. 2001, 70, 69-83.

[27] W. Shakespeare, Much Ado About Nothing. citation after Tobin [18]. 
204 [28] G.A. Tobin, Water promises: Much ado about nothing - as profitless as water in a sieve? 205 J. Contemp. Water Res. Educ. 2009, 142, 1-3.

206 [29] J.L. Schnoor, Announcing Environmental Science \& Technology Letters. Environ. Sci. 207 Technol. 2013, 47, 7579-7579.

208 [30] A. Berthod, So What? or required content of a review article. Sep. Purif. Rev. 2009, 38, $209 \quad$ 203-206. 